\title{
Effects of Dietary Supplementation at Nile tilapia with Thymus vulgaris, Trigonela foenum graecum and Azadirachta indica on Welfare Status
}

\author{
Alina ANTACHE*, Victor CRISTEA, Iulia GRECU, Lorena DEDIU, \\ Mirela CRETU, Elena BOCIOC, Stefan M. PETREA \\ Department of Aquaculture, Environmental Science and Cadastre, University "Dunarea de Jos" Galati, \\ Romania \\ *Corresponding author, email: antache_alina@yahoo.com
}

Bulletin UASVM Animal Science and Biotechnologies 71(2) / 2014,

Print ISSN 1843-5262; Electronic ISSN 1843-536X

DOI:10.15835/buasvmcn-asb:10386

\begin{abstract}
At fish, the evaluation of hematological profile is an important step in monitoring the welfare status. The aim of this research was to determine the influence of dietary supplementation with some phytobiotics on hematological profile, some biochemical indices of blood and on the immune response at Oreochromis niloticus reared in a recirculating aquaculture system. The experimental variants were organized as follows: V1-control, V2-1\% thyme, V3-1\% fenugreek and V4-1\% neem. Blood analysis, glucose and total protein were carried out by methods commonly used in fish hematology. Lysozyme activity was measured by a turbiometric assay and cortisol was determined by an immunoenzymatic assay. At the end of the experiment was observed that the phytobiotics administration has led to significant changes $(p<0.05)$ in case of erythrocytes number $(p=0.002)$ and relative number of monocytes $(\%)(\mathrm{p}=0.045)$. Comparing final results with the value obtained at the beginning of the experiment were noted significant differences $(p<0.05)$ in case of erythrocytes number $(p=0.037)$, PVC $(p=0.001)$, MCHC $(p=0.000)$, glucose $(p=0.035)$, monocytes $(\%)(p=0.042)$. The best values were registered in V2 and V3 variant. The concentration of cortisol was lower in variants in which the dietary was supplemented with phytobiotics compared to the control variant. The neem (V4) administration led to intensifying the lysozyme activity than other experimental variants. In conclusion, we demonstrated that the dietary supplementation especially with thyme and fenugreek, but also with neem has improved the physiological status at Oreochromis niloticus species.
\end{abstract}

Keywords: hematological profile, lysozyme, Nile tilapia, phytobiotics, recirculating aquaculture system

\section{INTRODUCTION}

Knowledge of the hematological characteristics is an important tool that can be used as an effective and sensitive index to monitor physiological and pathological changes in fishes (Satheeshkumar et al., 2011), but this can be influenced by growth conditions, sex, age, biochemical composition of feed, etc. (Patriche et al., 2011). The major hematopoietic organs in fish are the head kidney (Reavil and Roberts, 2007) with the spleen, epigonal organ and Leydig organ additionally participating in granulopoiesis (Ainsworth, 1992).
The analysis of blood indices has proven to be a valuable approach for analysing the health status of farmed animals as these indices provide reliable information on metabolic disorders, deficiencies and chronic stress status before they are present in a clinical setting (Bahmani et al. 2001).

Blood biochemistry parameters can be also used to detect the health of fish (De Pedro et al. 2005). The glucose and cortisol registered an increase when fishes are exposed to a stressor factor (Lermen et al., 2004) and total proteins represent the most important indicator of nutrition and health status in fish (Patriche et al., 2009). 
Fish nutrition researches have emphasized the importance of nutrients in maintaining normal immune function and resistance to disease (Blazer and Wolke, 1984, cited by Docan et al., 2012).

The administration of medicinal plant in fish feed is considered as a modern and promising alternative to antibiotics and vaccines as a prophylactic measure in intensive aquaculture. Various products derived from medicinal plants have been studied concerning their ability to preventing diseases in a variety of fish species (Raa, 2000; Haghighi and Rohani, 2013), establishing that they present immunostimulatory properties.

At the same time, herbal immunostimulants are substances which activate white blood cells (WBC) and may render fishes more resistant to infectious diseases, by the stimulating phagocytic cells as well as complement, lysozyme and antibody responses of fish (Secombes and Olivier, 1997).

The aim of this research was to investigate the influence of thyme, fenugreek and neem on hematological profile (red blood cell count, hematocrit, hemoglobin, erythrocyte constants, relative and absolute number of leucocyte) and some biochemical indices of blood (glucose, cortisol, total proteins, lysozyme activity) at Oreochromis niloticus species, reared in a recirculating aquaculture system.

\section{MATERIALS AND METHODS}

Experimental design. This experiment was conducted in the research laboratory of Aquaculture, Environmental Science and Cadastre Department from "Dunarea de Jos" University of Galati. This recirculating system was described in our precedent paper (Antache et al., 2013). The design of this system consists in four rearing units, with a volume of $1 \mathrm{~m}^{3}$ each, and a series of water quality conditioning units (Cristea et al., 2002). The experiment lasted six weeks, from 20.06.2012 to 1.08.2012.

In this research were used a total number of 180 exemplars of Nile tilapia, with an initial average weight of $125.41 \pm 34.33 \mathrm{~g} / \mathrm{fish}$, that were randomly distributed in four rearing units. Fish were fed with SOPROFISH pelleted feed, with $38 \%$ crude protein and $7 \%$ crude fat, the feed biochemical composition was related in Antache et al. (2013). The feeding frequency was 4 times per day, at an interval of 3 hours (9:00, 12:00,
$15: 00,18: 00)$ and was done manually. Daily ration was $3.4 \%$ of total body weight. At the end of the experiment, the individual average weight was $251.00 \pm 61.75 \mathrm{~g} /$ fish in V1, 268.33 $\pm 49.71 \mathrm{~g} /$ fish in V2, $253.89 \pm 53.68 \mathrm{~g} /$ fish in V3 and 251.56 \pm 56.46 $\mathrm{g} /$ fish in $\mathrm{V4}$.

The experimental variants were: V1-control, V2-1\% thyme (Thymus vulgaris)/kg feed, V3-1\% fenugreek (Trigonella foenum graecum) $/ \mathrm{kg}$ feed and $\mathrm{V} 4-1 \%$ neem (Azadirachta indica) $/ \mathrm{kg}$ feed. These phytobiotics were purchased from a Plafar market. Introduction of phytobiotics in feed was performed using an aqueous solution of gelatin with $2 \%$ concentration. The feed was sprayed, mixed and then dried at $25^{\circ} \mathrm{C}$.

Blood sampling and analysis. Blood sampling has been carried out at the beginning (Vi) and at the end of experiment. Was sampling $3.5 \mathrm{ml}$ of blood at 7 fish from each growth unit by caudal venous puncture using heparin as anticoagulant in eppendorfs for hematological parameters and in eppendorfs without heparin, for biochemical parameters. A part of the blood was used for hematological study also for determining glucose, cortisol, total protein and lysozyme activity, and the other part was used for analysis of oxidative stress that was the subject of another study (Antache et al. (2013).

Blood analysis was performed by method used in fish hematology described by Blaxhall (1973). This analysis consisted in determination of red blood cells count -RBCc $\left(\times 10^{6}\right.$ cells $\left./ \mathrm{mm}^{3}\right)$, hemoglobin - $\mathrm{Hb}(\mathrm{g} / \mathrm{dl})$ and hematocrit -PVC (\%). For determination of erythrocyte number was used the Neubauer hemocytometer, Potain pipette and Vulpian diluting solution. The hematocrit was performed by duplicate using capillary tubes centrifugated for 5 minutes at $12000 \mathrm{rpm}$ in a micro hematocrit centrifuge. The hemoglobin concentrations were measured spectrofotometrically with SPECORD 210 Analytikjena at $\lambda-540 \mathrm{~nm}$, using Drabkin reagent.

Then, using standard formulas described by Ghergariu et al. (1985) and Svobodova, (2001) were calculated the erythrocyte constants: mean corpuscular volume - $\mathrm{MCV}\left(\mu \mathrm{m}^{3}\right)$, mean corpuscular hemoglobin - $\mathrm{MCH}$ (pg), mean corpuscular hemoglobin concentration - MCHC ( $\mathrm{g} / \mathrm{dl})$.

Biochemical blood analysis consisted in determination of glucose $(\mathrm{mg} / \mathrm{dL})$, cortisol (ng/ $\mathrm{mL})$, total proteins $(\mathrm{g} / \mathrm{dL})$ and lysozyme activity 
(Units/mL). To obtain blood serum, the blood without anticoagulant was centrifuged 10 minutes, at 3500 rotations/min.

Determination of glucose, total protein and lysozyme activity from serum was performed spectrophotometric using the spectrophotometer SPECORD 210 Analytikjena and cortisol using an ELISA microwell plate reader.

Dosage of glucose was made by colorimetric method with o-toluidine and readings were made at a $635 \mathrm{~nm}$ wavelength. Total proteins from serum were determined by Biuret method, the readings were done at a $546 \mathrm{~nm}$ wavelength.

Lysozyme activity was measured, from serum, based on the turbiometric assay, Enzymatic Activity of Lysozyme Protocol (Sigma, EC 3.2.1.17). For this test was used as a substrate the Micrococcus lysodeikticus (Sigma, M3770), as a buffer Potassium Phosphate (with $6.24 \mathrm{pH}$ at $25^{\circ} \mathrm{C}$ ) and as an enzyme-lyophilised powder of chicken egg white lysozyme (Sigma, L6876). One unit of lysozyme activity was defined as a reduction in absorbancy of $0.001 / \mathrm{min}$ at a $450 \mathrm{~nm}$ wavelength.

Serum cortisol determination was performed using the kit: NovaTec Cortisol-DNOV001 based on competitive immunoenzymatic colorimetric method for quantitative determination of Cortisol in human serum or plasma. Absorption was read at $450 \mathrm{~nm}$.

The relative and absolute number of leucocyte was obtained by microscopic examination of 200 leukocytes on blood smears (two per each fish), using Zeizz Axio Imager microscope and immersion objective (10 oc. X 100 ob.). Absolute number of circulating blood leukocytes and thrombocytes was determined in comparison with 1000 erythrocytes counted on hemocytometer, per blood volume unit. The blood smears were colored with May-Grünwald Giemsa panoptic method (MGG) and the type of leukocytes were determined based on identification characters listed by Svobodova et al. (1991).

Before blood sampling, fish were anesthetized with 2-phenoxyethanol in order to reduce handling stress. Research has shown that 2-phenoxyethanol anesthetic had no effect on hematological profile (Velíšek et al., 2007).

Statistical analysis. The results, of hematological and biochemical parameters, of the experimental groups were statistically analyzed using descriptive statistics and ANOVA One Way test. Programs used were Microsoft Excell (Office 2010) and SPSS Statistics 20.0 for Windows. The results were presented as mean \pm standard deviation.

\section{RESULTS AND DISCUSSION}

For monitoring the physiological and pathological changes, in fish, the knowledge of hematologic characteristics plays a very important role (Kori-Siakpere et al., 2005). Regarding the hematological and biochemical parameters the results are presented in Table 1.

At the end of the research between experimental variants were obtained significant differences $(p<0.05)$ in case of RBCc $(p=0.011)$, but between initial and final values were registered significant differences $(p<0.05)$ in case of RBCc $(p=0.037)$, PVC $(p=0.001)$, MCHC $(p=0.000)$ and GLU (0.035).

Tab. 1. Variation of hematological and biochemical parameters during the experiment

\begin{tabular}{|c|c|c|c|c|c|c|}
\hline \multirow{2}{*}{\multicolumn{2}{|c|}{$\begin{array}{c}\text { Experimental stage } \\
\text { Experimental variant }\end{array}$}} & \multirow{3}{*}{$\begin{array}{c}\frac{20.06 .2012}{\mathrm{Vi}} \\
1.793 \pm 0.56\end{array}$} & \multicolumn{4}{|c|}{1.08 .2012} \\
\hline & & & \multirow{2}{*}{$\frac{\mathrm{V} 1}{1.609 \pm 0.14}$} & \multirow{2}{*}{$\frac{\mathrm{V} 2}{1.972 \pm 0.15}$} & \multirow{2}{*}{$\frac{\mathrm{V} 3}{2.066 \pm 0.27}$} & \multirow{2}{*}{$\frac{\mathrm{V} 4}{1.664 \pm 0.20}$} \\
\hline \multirow{8}{*}{ 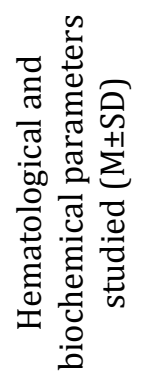 } & $\mathrm{RBCc}\left(\mathrm{x} 10^{6} / \mu \mathrm{L}\right)^{\mathrm{ab}}$ & & & & & \\
\hline & PVC $(\%)^{b}$ & $20.69 \pm 4.10$ & $25.60 \pm 4.18$ & $30.00 \pm 1.10$ & $30.20 \pm 2.56$ & $26.60 \pm 3.07$ \\
\hline & $\mathrm{Hb}(\mathrm{g} / \mathrm{dL})^{\mathrm{c}}$ & $10.12 \pm 1.76$ & $8.45 \pm 1.37$ & $8.47 \pm 0.54$ & $8.60 \pm 0.58$ & $8.49 \pm 1.94$ \\
\hline & $\operatorname{MCV}\left(\mu \mathrm{m}^{3}\right)^{\mathrm{c}}$ & $121.58 \pm 28.51$ & $160.01 \pm 28.34$ & $152.75 \pm 8.89$ & $148.56 \pm 20.76$ & $162.30 \pm 28.13$ \\
\hline & $\mathrm{MCH}(\mathrm{pg})^{\mathrm{c}}$ & $60.57 \pm 18.22$ & $53.13 \pm 10.70$ & $43.16 \pm 4.11$ & $42.27 \pm 6.00$ & $52.02 \pm 14.37$ \\
\hline & MCHC $(\mathrm{g} / \mathrm{dL})^{\mathrm{b}}$ & $49.80 \pm 8.37$ & $46.09 \pm 3.62$ & $39.32 \pm 3.15$ & $39.99 \pm 5.15$ & $43.90 \pm 5.65$ \\
\hline & GLU $(\mathrm{mg} / \mathrm{dL})^{\mathrm{c}}$ & $67.31 \pm 4.95$ & $87.96 \pm 9.73$ & $82.46 \pm 15.39$ & $85.29 \pm 3.71$ & $99.27 \pm 20.73$ \\
\hline & $\mathrm{TP}(\mathrm{g} / \mathrm{dL})^{\mathrm{b}}$ & $5.74 \pm 0.32$ & $6.30 \pm 0.53$ & $6.04 \pm 0.36$ & $6.10 \pm 0.58$ & $6.71 \pm 0.79$ \\
\hline
\end{tabular}

"a" - significant differences between variants at the end of the experiment $(p<0.05)$;

"b" - significant differences between initial and final experimental variants $(p<0.05)$;

"c" - insignificant differences ( $p>0.05)$. 
In terms of red blood cells count, was registered a significant increase $(\mathrm{p}<0.05)$ in variant in which was administered fenugreek in feed (V3). Although, at end of the experiment were recorded significant differences, the red blood cells count was within of reference range for the species Oreochromis niloticus, $0.7-2.8 \times 10^{6} / \mu \mathrm{L}$ (Bittencourt et al., 2003).

Hematocrit percentage recorded the highest values in variant V3 and V2 and the lowest value was obtained in variant V1. Nevertheless, between experimental variants were not observed significant differences $(\mathrm{p}<0.05 ; \mathrm{p}=0.093)$, but compared to the value recorded at the beginning of the experiment were registered a significant increase $(\mathrm{p}<0.05 ; \mathrm{p}=0.001)$ in variants V3 and V2. Increase of hematocrit percentage in these variants (V and V3) shows that the administered feed was used efficiently, but also that the fish shows a good health condition. Similar observations were reported by Aly et al. (2008) in case of dietary supplementation with different probiotics at Nile tilapia. However, the values obtained during the experiment were within the optimal range for our studied species, respectively between $15-47 \%$ (Bittencourt et al., 2003).

At the end of the experiment, the concentration of hemoglobin registered a decrease with $16.50 \%$ in variant $\mathrm{V} 1,16.30 \%$ in variant $\mathrm{V} 2,16.11 \%$ in variant V4, respectively with $15.02 \%$ in variant V3 compared to Vi. But, those changes were not statistically significant $(p<0.05 ; p=0.182)$, and the values were within the reference range (6.58$15.98 \mathrm{~g} / \mathrm{dL}$ ) for Oreochromis niloticus species, reported by Bittencourt et al. (2003).

Concerning the erythrocyte constants, at end of the experiment were not recorded significant differences $(\mathrm{p}<0.05)$ between the experimental variants in case of MCV ( $p=0.819), \operatorname{MCH}(p=0.279)$ and MCHC $(p=0.149)$. Values obtained are found in the reference range: MCV-20-214 $\mu \mathrm{m}^{3}$ (Hamid et al., 2013), MCH-5.0-80.4 pg (Hamid et al., 2013), MCHC-19.84-87.73 g/dL (Bittencourt et al., 2003).

At the end of the experiment, the results showed a significant increase $(\mathrm{p}<0.05 ; \mathrm{p}=0.035)$ in glucose concentration compared to the value obtained at the beginning of the experiment. In this research, only the Thymus vulgaris led to obtaining the lowest glucose values among the three phytobiotics administered.
In terms of serum total proteins were not registered significant differences $(p>0.05)$ between experimental variants $(\mathrm{p}=0.418)$, and nor from the value obtained at the beginning of the experiment $(p=0.174)$. The results were registered in the reference range: 4.8-7.8 g/dL (Hrubec et al., 2000).

Besides the determination of glucose and total proteins for more accurate assessment of health status was performed the determination of cortisol and lysozyme activity.

After six weeks of the experiment, cortisol values showed not significant differences between the experimental variants $(\mathrm{p}>0.05 ; \mathrm{p}=$ 0.98). But, is observed a decrease of cortisol in variants in which the diet was supplemented with phytobiotics compared to the control variant -V1 (with 4.29\% in V2, 6.40\% in V3 and 8.99\% in V4). Apines-Amar et al. (2013) reported a reduction of cortisol values at $E$. fuscoguttatus species in case of dietary supplementation with some phytobiotics. Cortisol variation for each experimental variant is shown in Figure 1.

Regarding lysozyme activity, were not observed significant differences between the experimental variants $(\mathrm{p}<0.05 ; \mathrm{p}=0.266)$. However, compared to the control variant was registered an increase of lysozyme activity with $6.75 \%$ in variant V4 and a decrease with $16.00 \%$ in variant V3, respectively with $17.74 \%$ in variant V2. The variation of lysozyme activity is presented in Fig. 2.

Many studies have reported for the activity of lysozyme at Nile tilapia an interval ranged between 8.73-10.22 U/mL when was administered vitamin $\mathrm{C}$ and inulin (Ibrahem et al., 2010) and between 9.06 and $13.46 \mathrm{U} / \mathrm{mL}$ in case of probiotics administration (Aly et al., 2008).

For a better analysis of hematological profile was determined the relative (leukogram \%) and absolute number of leukocytes, because it is known that leukocytes play an important role in body defense at the contact with a pathogenic agent or in case of stress occurrence due to various internal or external factors.

Microscopic analysis of blood smears revealed the presence of small lymphocytes, large lymphocytes, monocytes and of neutrophil granulocytes. Eosinophil and basophil granulocytes were absent from blood smears. The blood cells morphology found on blood smears, can be seen in figure Figure 3. 


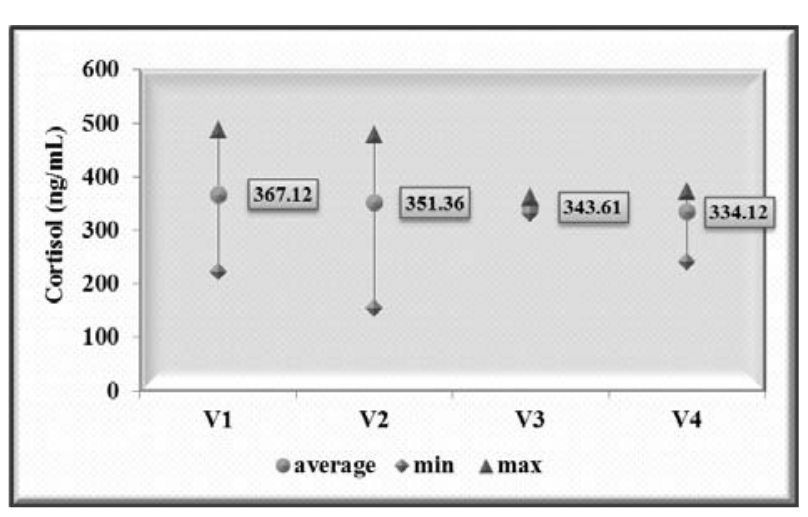

Fig. 1. Variation in serum cortisol at Oreochromis niloticus species

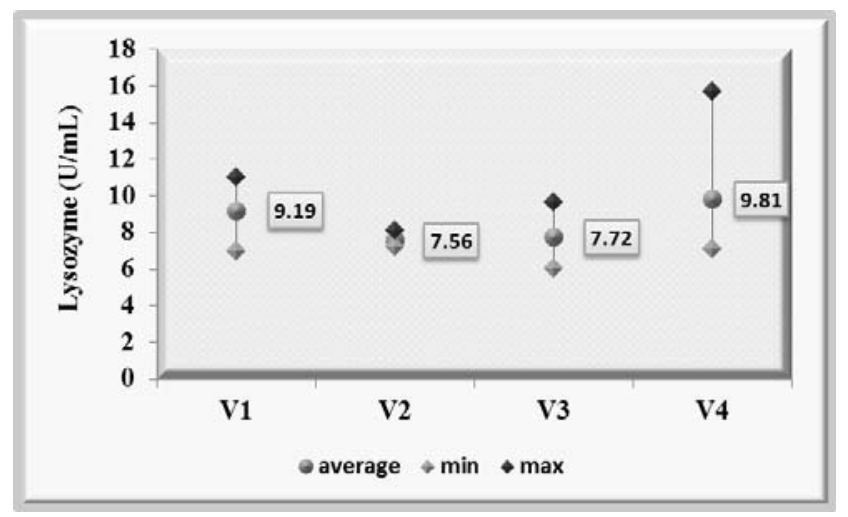

Fig. 2. Variation of lysozyme activity from serum at Oreochromis niloticus species

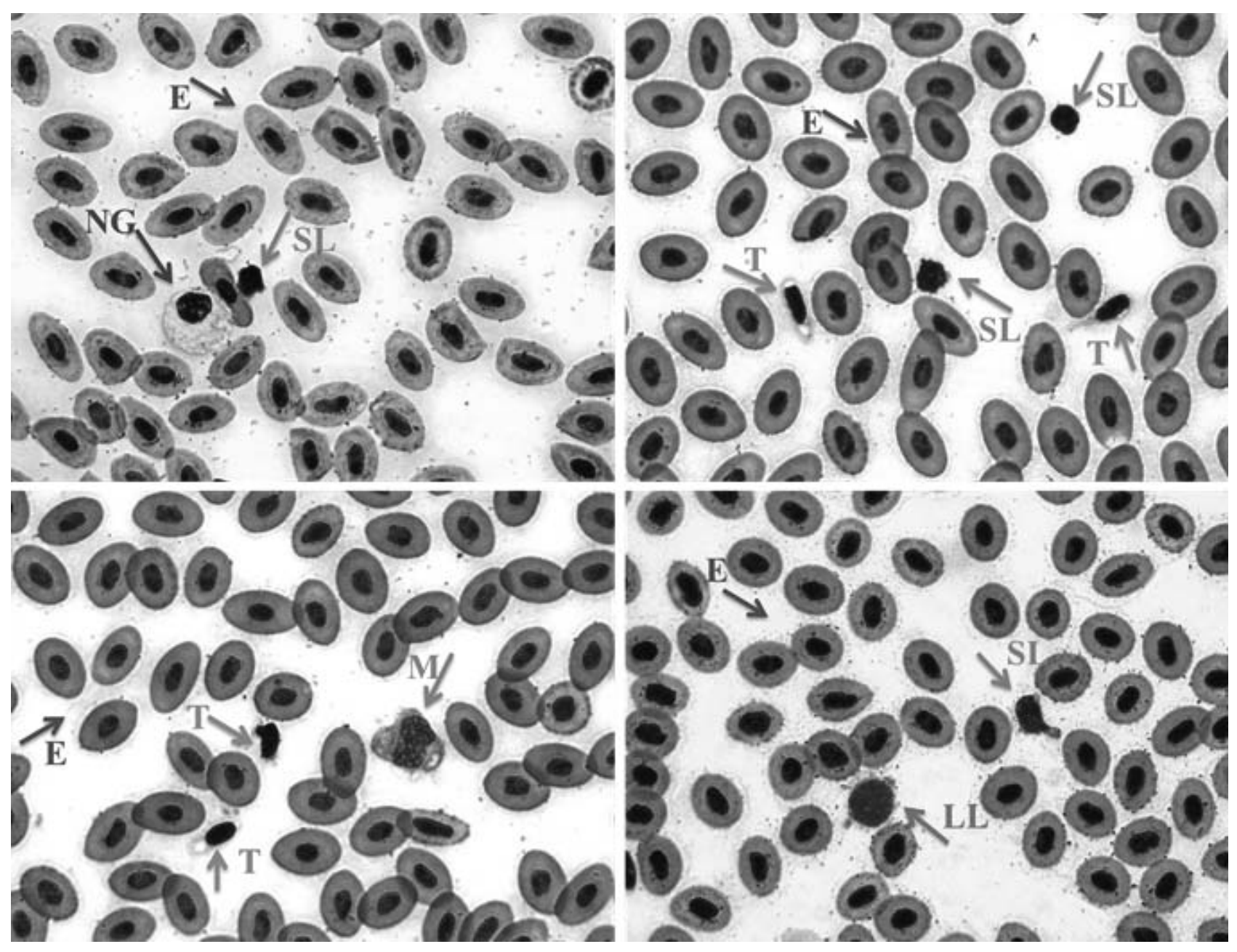

Fig. 3. Morphology of blood cells at Nile tilapia found on blood smears (photo original) Note: E-erythrocytes; SL-small lymphocyte; LL-large lymphocyte; M-monocytes; NG-neutrophilic granulocyte; T-thrombocyte. 
Tab. 2. Absolute and relative number of leukocytes at Oreochromis niloticus species

\begin{tabular}{|c|c|c|c|c|c|}
\hline $\begin{array}{c}\text { Experimental } \\
\text { variants }\end{array}$ & $\mathrm{Vi}$ & V1 & V2 & V3 & V4 \\
\hline \multicolumn{6}{|c|}{ Absolute number $\left(\mathrm{x} 10^{3}\right.$ cells $\left./ \mu \mathrm{L}\right)$} \\
\hline Leukocytes $^{c}$ & $79.88 \pm 37.00$ & $58.85 \pm 9.30$ & $60.40 \pm 8.17$ & $71.65 \pm 11.68$ & $53.18 \pm 10.12$ \\
\hline Small lymphocytes ${ }^{c}$ & $78.22 \pm 36.65$ & $57.37 \pm 8.98$ & $58.09 \pm 8.84$ & $70.13 \pm 11.61$ & $51.82 \pm 9.83$ \\
\hline Large lymphocytes $^{\mathrm{c}}$ & $0.37 \pm 0.22$ & $0.52 \pm 0.16$ & $0.43 \pm 0.30$ & $0.53 \pm 0.15$ & $0.55 \pm 0.44$ \\
\hline Monocytes $^{c}$ & $0.41 \pm 0.21$ & $0.28 \pm 0.05$ & $0.69 \pm 0.35$ & $0.33 \pm 0.04$ & $0.33 \pm 0.15$ \\
\hline Neutrophils $^{c}$ & $0.89 \pm 0.75$ & $0.68 \pm 0.20$ & $1.18 \pm 0.66$ & $0.66 \pm 0.18$ & $0.49 \pm 0.22$ \\
\hline Thrombocytes $^{c}$ & $13.07 \pm 10.39$ & $20.57 \pm 4.45$ & $27.68 \pm 9.63$ & $21.54 \pm 14.97$ & $16.32 \pm 5.11$ \\
\hline \multicolumn{6}{|c|}{ Relative number / leukogram (\%) } \\
\hline Small lymphocytes ${ }^{\mathrm{c}}$ & $97.71 \pm 0.85$ & $97.50 \pm 0.40$ & $95.89 \pm 2.50$ & $97.83 \pm 0.34$ & $97.52 \pm 0.96$ \\
\hline Large lymphocytes $^{c}$ & $0.66 \pm 0.27$ & $0.86 \pm 0.18$ & $0.76 \pm 0.52$ & $0.75 \pm 0.21$ & $0.99 \pm 0.81$ \\
\hline Monocytes $^{\text {ab }}$ & $0.55 \pm 0.21$ & $0.48 \pm 0.03$ & $1.24 \pm 0.71$ & $0.47 \pm 0.03$ & $0.59 \pm 0.18$ \\
\hline Neutrophils $^{c}$ & $1.08 \pm 0.67$ & $1.16 \pm 0.26$ & $2.11 \pm 1.42$ & $0.95 \pm 0.31$ & $0.89 \pm 0.34$ \\
\hline
\end{tabular}

"a" - significant differences between variants at the end of the experiment $(\mathrm{p}<0.05)$;

" $\mathrm{b}$ " - significant differences between initial and final experimental variants $(\mathrm{p}<0.05)$;

" $c$ " - insignificant differences ( $p>0.05)$.

Analysis of blood smears showed us a good physiological state of fish by the absence of eosinophils and basophil granulocytes, their presence indicating the occurrence of an inflammatory process.

In Table 2 are presented the absolute and relative number of leukocytes and absolute number of thrombocytes.

In terms of relative number of leukocytes were recorded significant differences between final variants in case of monocytes $(\%)(p<0.05$; $\mathrm{p}=0.045$ ) and between initial value and final variants also in case of monocytes $(\%)(p<0.05$; $\mathrm{p}=0.042$ ). The highest value was recorded in variant V2 and the lowest in variant V3. Relative number of small lymphocytes, large lymphocytes and neutrophils not registered significant differences between the experimental variants $(p<0.05)$ and neither against the value obtained at the beginning of the experiment $(\mathrm{p}<0.05)$.

Absolute number of leukocytes recorded an increase, but not significant $(\mathrm{p}<0.05 ; \mathrm{p}=0.149)$, in variant V2 with $2.63 \%$, respectively with $21.75 \%$ in variant V3 compared to control variant V1. We can say that dietary supplementation at Nile tilapia with fenugreek and thyme in $1 \%$ concentration led to the improvement of immunity. Results fall in the optimal range for Oreochromis niloticus species (Hrubec et al., 2000).
At the end of the experiment, were not registered significant differences $(\mathrm{p}<0.05)$ between experimental variants in terms of absolute number of small lymphocytes $(\mathrm{p}=0.150)$, large lymphocytes $(p=0.960)$, monocytes $(p=0.053)$ and of neutrophils $(\mathrm{p}=0.137)$. Values obtained during the experiment were recorded in the optimal range for Nile tilapia (Hrubec et al., 2000).

Regarding the absolute number of thrombocytes, was observed an increase, but not significant $(\mathrm{p}<0.05 ; \mathrm{p}=0.508)$, with $34.56 \%$ in variant $\mathrm{V} 2$, respectively with $4.72 \%$ in variant V3. Recent studies have shown that thrombocytes are involved in hemostasis process and play a defending role in organism, it is products in teleostean fish in the spleen and kidneys (Tavares-Dias and Oliveira, 2009). So, we can say that thyme and fenugreek led to improve the immunity by increasing the absolute number of thrombocytes. Values of thrombocytes obtained during the experimental period were registered in reference interval (2.00$78.90 \times 10^{3}$ cells $\left./ \mu \mathrm{L}\right)$ described by Tavares-Dias and Oliveira (2009).

\section{CONCLUSION}

As a first conclusion, we can say that the hematological profile analysis revealed that dietary supplementation with thyme and fenugreek in concentration of $1 \%$ at Nile tilapia, for six weeks, led to improved the physiological 
functions at the end of the experiment due to obtaining a hemoconcentration increased. This is being achieved with increasing of red blood cell count (RBCc), hematocrit (PVC), mean corpuscular hemoglobin $(\mathrm{MCH})$ and mean corpuscular hemoglobin content (MCHC).

The significant increase of hematocrit in case of feed supplementation with thyme (V2) and fenugreek (V3), compared to the value obtained at the beginning of the experiment $(\mathrm{p}<0.05$; $\mathrm{p}=0.001$ ), indicating the safe use of these phytobiotics and their efficiency on health status. A low hematocrit may lead to an efficient feeding and an easy occurrence of certain disease states.

From phytobiotics used, thyme and fenugreek led to lower values of glucose, but the lowest values of plasma cortisol were obtained in case of neem, fenugreek and thyme administration. These indicators stay at the base of a faster analysis of stress in fish.

Higher value of lysozyme activity was registered in case of diet supplementation with neem, this aspect showing the presence of positive effects on immunity.

Increased of leucocyte count, at the end of the experiment, in variants V 2 and $\mathrm{V} 3$ can be correlated with an increased production of antibodies. Which leads to ensure the technological comfort conditions, fish being less affected in case of a stressor factor or diseases occurrence.

The significant increase in the relative number of monocytes obtained in V2, may be associated with an increase in cellular defense mechanisms of the organism.

Regarding leukogram (\%), the percentage of small lymphocytes indicates immunomodulating effects of phytobiotics used, respectively immunostimulation in variants V3 (fenugreek) and V2 (thyme) and immunosuppression in V4 (neem).

In conclusion, we demonstrated that the dietary supplementation especially with thyme and fenugreek, but also with neem has improved the physiological status at Oreochromis niloticus species.

Acknowledgments. The work of Alina Antache and Stefan Mihai Petrea has been funded by the Sectoral Operational Programme Human Resources Development 2007-2013 of the Ministry of European Funds through the Financial Agreement POSDRU/159/1.5/S/132397 - ExcelDOC. The work of coauthor Elena Bocioc was supported by Project SOP HRD - PERFORM /159/1.5/S/138963.

\section{REFERENCES}

1. Ainsworth AJ (1992). Fish granulocytes, morphology, distribution, and function. Ann. Rev. Fish Dis. 2:123-148.

2. Aly SM, YA-G Ahmed, AA-A Ghareeb and MF Mohamed (2008). Studies on Bacillus subtilis and Lactobacillus acidophilus, as a potential probiotics, on the immune response and resistance of Tilapia nilotica (Oreochromis niloticus) to challenge infections. Fish and Shellfish immunology 25:128-136.

3. Antache A, V Cristea, Dediu, I Grecu, A Docan, I Vasilean, M Mocanu (Crețu) and Șt M Petrea (2013). The influence of some phytobiotics on growth performance at Oreochromis niloticus reared in an intensive recirculating aquaculture system. Lucrări Ştiinţifice-Seria Zootehnie, 60:204-208.

4. Antache A, V Cristea, I Grecu, L Dediu, A Docan, M (Crețu) Mocanu, S (Ion) Plăcintă and MT Coadă (2013). The influence of some phytobiotics on oxidative stress at Oreochromis niloticus grown in an intensive recirculating aquaculture system. Lucrări Ştiinţifice-Seria Zootehnie 59(18): 253-257.

5. Apines-Amar MJS, EC Amar and JP Faisan Jr (2013). Growth, plasma cortisol, liver and kidney histology, and resistance to vibriosis in brownmarbled grouper, Epinephelus fuscoguttatus fed onion and ginger. Aquaculture, Aquarium, Conservation \& Legislation, International Journal of the Bioflux Society, AACL Bioflux, 6(6): 530-538.

6. Bahmani M, R Kazemi and P Donskaya (2001). A comparative study of some hematological features in young reared sturgeons (Acipenser persicus and Huso huso). Fish Physiol Biochem 24:135-140.

7. Bittencourt NLR, LM Molinari, DO Scoaris, RB Pedroso, CV Nakamura, T Ueda-Nakamura, BAA Filho and BPD Filho (2003). Haematological and biochemical values for Nile tilapia Oreochromis niloticus cultured in semi-intensive system. Acta Scientiarum. Biological Sciences Maringá 25(2): 385-389.

8. Blaxhall PC and KW Daisley (1973). Routine Haematological Methods For Use Fish Blood. Journal of Fish Biology 5(6): 771-781.

9. Blazer VS and RE Wolke (1984). The effects of a-tocopherol on the immune response and non-specific resistance factors of rainbow trout (Salmo gairdneri Richardson). Aquaculture 37:1-9 cited by Docan, A., L. Dediu and V. Cristea (2012). Effect of feeding with different dietary protein level on leukocytes population in juvenile Siberian sturgeon, Acipenser baeri Brandt. Archiva Zootechnica 15(4): 59-67.

10. Cristea V, I Grecu and C Ceapa (2002). Recirculating aquaculture systems engineering. Didactic and Pedagogic Publishing House, R. A. Bucharest.

11. De Pedro N, AE Guijarro, MA Lopez-Patino, R MarinezAlvarez and M Delgado (2005). Daily and seasonal variation in haematological and blood biochemical parameters in tench Tinca tinca. Aquaculture Res 36:8596. 
12. Ghergariu S, A Pop and L Kadar (1985). Ghid de Laborator Clinic Veterinar, București.

13. Haghighi M and MS Rohani (2013). The effects of powdered ginger (Zingiber officinale) on the haematological and immunological parameters of rainbow trout Oncorhynchus mykiss. J. Med. Plant Herbal Ther. Res. 8-12.

14. Hamid ASH, MFA Ahmed, AMI Mohammed and MSI Ali (2013). Physical and chemical caracteristics of blood of two fish species (Oreochromis niloticus and Clarias lazera). Worlds Vet. J. 3(1): 17-20.

15. Hrubec TC, JL Cardinale and SA Smith (2000). Hematology and Plasma Chemistry Reference Intervals for Cultured Tilapia (Oreochromis Hybrid). Veterinary Clinical Pathology 29(1):7-12.

16. Ibrahem MD, M Fathi, S Mesalhy and AMA El-Aty (2010). Effect of dietary supplementation of inulin and vitamin $\mathrm{C}$ on the growth, hematology, innate immunity, and resistance of Nile tilpia (Oreochromis niloticus). Fish and Shellfish Immunology 29:241-246.

17. Kori-Siakpere O, JEG Alje and E Idoge (2005). Haematological characteristcs of the African snakehead, Parachacnna obscura. Afr J Biotechnology 4(6): 527-530.

18. Lermen CL, R Lappe, M Crestani, VP Vieira, CR Gioda, MRC Schetinger, B Baldisserotto, G Moraes and VM Morsch (2004). Effect of different temperature regimes on metabolic and blood parameters of silver catfish Rhamdia quelen. Aquaculture 239:497-507.

19. Patriche T, N Patriche and M Tenciu (2009). Cyprinids total blood proteins determination Lucrări știinţifice Zootehnie şi Biotehnologii 42(2): 95-101.

20. Patriche T, N Patriche, E Bocioc and MT Coada (2011). Serum biochemical parameters of farmed carp (Cyprinus carpio). Aquaculture, Aquarium, Conservation and Legislation - International Journal of the Bioflux Society 4:137-140.

21. Raa J (2000). The use of immunostimulants in fish and shellfish feeds. In: Cruz-Suarez, LE, D Ricque-Marie, M Tapia-Salazar, MAY Olvera-Novoa and R Civera-Cerecedo (Eds.). Avances en Nutrición Acuícóla V. Memorias del V Simposium International de Nutrición Acuícóla. Merida, Yucatan, Mexico, 47-56.

22. Reavill D and H Roberts (2007). Diagnostic cytology of fish. Vet. Clin. Exot. Anim. 10:207-234.

23. Satheeshkumar P, G Ananthan, D Senthil Kumar and L Jagadeesan (2011). Haematology and biochemical parameters of different feeding behaviour of teleost fishes from Vellar estuary, India. Comp Clin Pathol, DOI 10.1007/ s00580-011-1259-7.

24. Secombes CJ and G Olivier (1997). Furunculosis. Academic Press, New York, 269-296.

25. Svobodova Z, D Fravda and J Palakova (1991). Unified methods of haematological examination of fish. Research Institute of fish Culture and Hydrobiology, VURH Vodnany, Edice Metodik, Czechoslovakia.

26. Svobodova Z (2001). Stress in Fishes (A Review). Bull. Vurh Vodnany 4:169-191.

27. Tavares-Dias M and SR Oliveira (2009). A review of the blood coagulation system of fish. Brazilian Journal of Biosciences, Porto Alegre 7(2): 205-224.

28. Velíšek J, Z Svobodová and V Piačková (2007). Effects of 2-Phenoxyethanol Anaesthesia on Haematological Profile on Common Carp (Cyprinus carpio) and Rainbow Trout (Oncorhynchus mykiss). Acta Vet. Brno 76:487-492. 